УДК 621.311.69:681.586.7

\author{
${ }^{[0000-0002-2354-9106]}$ М. Г. Томенко, к.пед.н., \\ e-mail: marina_tomenko@ukr.net \\ ${ }^{[0000-0001-7139-9141]}$ B. І. Томенко, к.т.н., доиент \\ e-mail: firech1996@gmail.com \\ Черкаський інститут пожежної безпеки імені Героїв Чорнобиля \\ Національного університету цивільного захисту України \\ вул. Онопрієнка, 8, м. Черкаси, 18034, Україна

\section{МАТЕМАТИЧНА МОДЕЛЬ СИСТЕМИ РАННЬОГО ВИЗНАЧЕННЯ АВАРІЙНОСТІ СКЛАДНИХ ТЕХНОЛОГІЧНИХ ВИРОБНИЦТВ НА БАЗІ АВТОНОМНИХ П'СЗОТРАНСПОНДЕРІВ}

В роботі запропоновано математичну модель системи попереднього визначення аварійності складних технологічних виробництв на потенційно небезпечних об'єктах або об'єктах підвищеної небезпеки, яка побудована на принципі фіксачії змін вібраџї̈ обладнання, щзо передує будь-якій аварії. Модель враховує основні складові системи: час передачі аварійної інформачії, різні типи енергоспоживання тощо. Проведені експериментальні дослідження на базі виявлення змін вібрачії при обертальних рухах робочих валів показали адекватність отриманої математичної моделі. Різниця між значеннями теоретичних розрахунків та експериментально отриманими даними не перевищувала $23 \%$. Отримана математична модель може бути використана розробниками при побудові ефективних протиаварійних систем на складних технологічних виробництвах потенційно небезпечних об'єктів або об 'єктів підвищеної небезпеки.

Ключові слова: математична модель, аварійні ситуачії, n'єзотранспондер, вібрачія, енергія.

Вступ. Для раннього визначення аварійних ситуацій та аварій на потенційно небезпечних об'єктах або об'єктах підвищеної небезпеки в складних технологічних процеcax важливим фактором $\epsilon$ постійний контроль над станом технологічного обладнання, оскільки будь-якій аварії передує незначна або суттєва зміна в параметрах і характеристиках обладнання: зміна струмів, механічних коливань тощо.

Для виявлення відхилень механічних (вібраційних) коливань, що притаманні майже будь-якому складному технологічному обладнанню, широко застосовують п'єзокерамічні перетворювачі $[1,2]$. Величезною їх перевагою $є$ те, що вони є активними, тобто під дією механічного впливу п'єзодатчики генерують електричну напругу, що буде слугувати джерелом живлення передавача [3].

В роботі [1] здійснено розробку п'єзокерамічних автономних датчиків 3 можливістю ідентифікації, що дозволило використовувати їх у системах раннього визначення аварійності складних технологічних виробництв. Загальний принцип роботи п'єзотранспондера як датчика зображено на рисунку 1.

Під впливом вібрації від технологічного обладнання відбувається живлення датчика (1) за рахунок прямого п'єзоефекту, коли вібрація механічно впливає на п'єзоелемент. При зміні вібраційної картини, що говорить про наявність аварійного стану на об'єкті, п'єзоперетворювач фіксує відхилення технологічного процесу від заданого і дистанційно по безпровідному каналу передає ідентифікаційний сигнал тривоги (2). Причому при необхідності за допомогою приймальнопередавального пристрою можна в будь-який час провести повірку роботоздатності датчика (3).

За цією схемою датчик будується за принципом п'єзотранспондера, коли конструктивні елементи датчика слугують ідентифікаторами елемента. Як такий ідентифікатор у п'єзоперетворювачах авторами запропоновано використовувати форми та розміри електродів $[1,2,4]$. Принцип роботи п'єзотранспондера зображено на рисунку 2. 


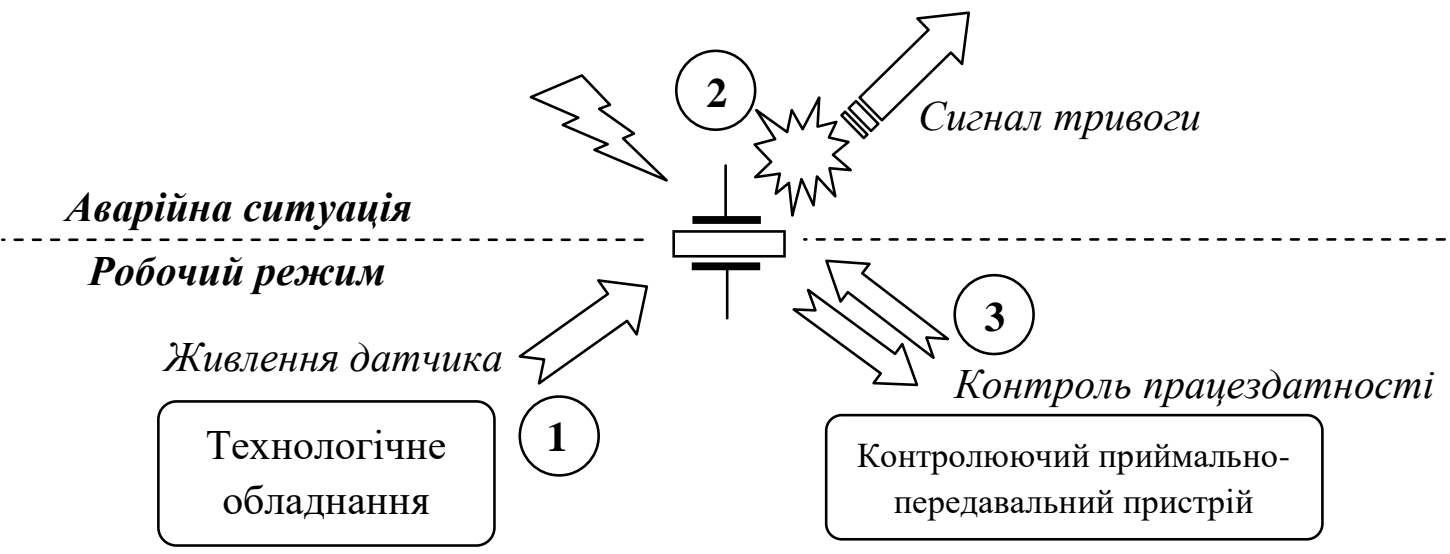

Рисунок 1 - Принцип роботи п'єзотранспондера як датчика

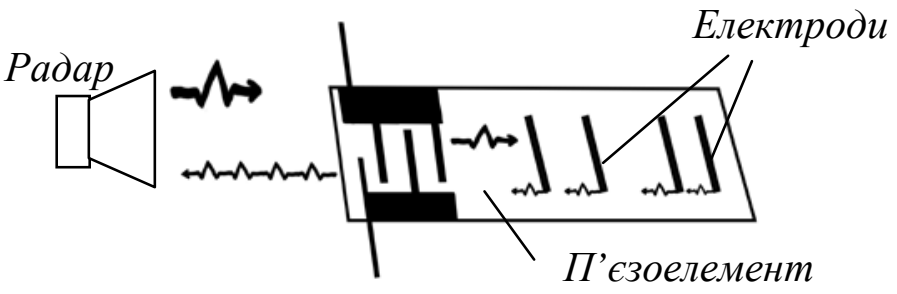

Рисунок 2 - П'єзоперетворювач як транспондер

Для ідентифікації датчика використовується принцип RFID-міток (Radio Frequency Identification), проте використовуються не мікроконтролери, а поверхнево акустичні хвилі на поверхні п'єзокерамічних елементів. Принцип роботи пристрою детально описаний в [4].

Проте для побудови розширеної системи складного технологічного процесу необхідно застосовувати велику кількість подібних датчиків, які повинні працювати в єдиній ідентифікаційній системі, в якій контролюються як живлення системи від стаціонарних джерел напруги (батарейне/акумуляторне, від мережі, регенераційне), так і можливість спрацювання при відсутності стаціонарного живлення від енергії, що накопичується від п’єзоперетворювачів.

Для побудови ефективної системи попереднього визначення аварійності складних технологічних виробництв необхідно розробити математичну модель, яка буде враховувати усі необхідні показники, що й було метою роботи.

Виклад основного матеріалу. При побудові математичної моделі, в першу чергу, необхідно визначити вхідні, вихідні, а також змінні складові, які необхідно враховувати при побудові математичної моделі системи раннього визначення аварійності складних технологічних процесів. Всі перераховані складові відображено на рисунку 3.

В системі до вхідних складових відносять:

$T$ - кількість контрольних точок, в яких визначаються параметри вібрації, тобто точки можливого розміщення п'єзотранспондерів. У простому випадку це може відповідати кількості технологічного обладнання, проте в більшості випадків на обладнанні може бути розміщено декілька контрольних точок, $i=\overline{1, t}$;

$j=\frac{P-}{1, p} ; \quad$ кількість п’єзотранспондерів, п'єзотранспондера (визначення аварійності) для кожного $j$-го транспондера;

$E_{B X}^{j}-$ енергія, яка попередньо накопичена в системі (для кожного $j$-го транспондера).

До вихідних величин належать:

S - матриця значень можливих розміщень п'єзотранспондерів у контрольних точках; 
$t_{j}$ - час передачі аварійного сигналу $j$-м п'єзотранспондером;

А - вектор-стрічка фіксації передачі ідентифікаційного аварійного сигналу.
До змінних величин належать:

$t_{\text {нор }}-$ нормований (необхідний) час передачі аварійного сигналу;

$V_{i}$ - параметри вібрації в $i$-й контрольній точці.

\section{Вхідні складові:}

$T$ - кількість контрольних точок; $P$ - кількість п'єзотранспондерів;

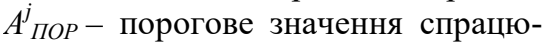
вання п'єзотранспондера; $E_{B X}^{j}-$ енергія, яка попередньо накопичена в системі.

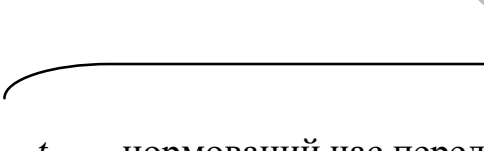

Змінні величини:

$t_{\text {нор }}$ - нормований час передачі аварійного сигналу; $V_{i}-$ параметри вібрації ного сигналу; сацій аварій

\section{Вихідні складові:}

S - матриця значень можливих розміщень п’єзотранспондерів;

$t_{j}$ - час передачі аварій-

А - вектор-стрічка фік-

Рисунок 3 - Модель складу основних компонентів при побудові математичної моделі

У векторі-стрічці фіксації передачі ідентифікаційного аварійного сигналу А елементи мають значення:

- $a_{j}=1$, якщо $j$-й п’єзотранспондер передає сигнал тривоги;

- $a_{j}=0$, якщо $j$-й п'єзотранспондер не визначає аварійну ситуацію.

Для успішної передачі інформації про наявність аварії, тобто за умови набуття будьяким із $j$ транспондерів у точці $i$ значення, більшого за $A_{\text {ПоР }}^{j}$, необхідно виконання умови

$$
t_{j} \geq t_{\text {нор }}
$$

для кожного $j$-го п'єзотранспондера.

Матриця значень можливих розміщень п'єзотранспондерів у контрольних точках

$$
\mathbf{S}=\left[s_{i j}\right]_{\substack{i=1 \ldots t \\ j=1 \ldots p}}
$$

визначається за такою умовою:

$-s_{i j}=1$, якщо $j$-й п’єзотранспондер знаходиться в $i$-й точці;

$-s_{i j}=0$, якщо $j$-й п'єзотранспондер не знаходиться в $i$-й точці.

Головною метою побудови математичної моделі $\epsilon$ визначення найефективнішого способу побудови системи раннього визначення аварійності складних технологічних процесів. Для цього необхідно розмістити $P$ транспондерів у $T$ контрольних точках таким чином, щоб спрацювання при аварії однозначно було виявлено і щоб аварійна інформація була гарантовано передана віддаленому вузлу обробки інформації. Це досягається виконанням умови

$$
\sum_{j=1}^{p} E_{B X}^{j}+\sum_{i=1}^{t} \sum_{j=1}^{p} E_{j}^{i} s_{i j} \rightarrow \min
$$

де $E_{j}^{i}$ - енергія, яка генерується на $j$-му п’єзотранспондері під впливом вібрації в $i$-й контрольній точці та визначається виразом

$$
E=d_{k l} F^{2},
$$

де $F$ - сила, що діє на п'єзоелемент під впливом вібрації; $d_{k l}-$ п'єзомодуль, де значення $k$ та $l$ визначаються напрямком вектора поляризації п'єзоелемента та сили, що діє на п’єзоелемент [3].

Враховуючи той факт, що енергія, яка генерується на п'єзоелементі, може бути меншою за енергію споживання елементами електронної схеми, для гарантованої передачі аварійного сигналу необхідно виконання умови для кожного $j$-го п’єзотранспондера:

$$
E_{B X}^{j}+E_{j}^{i} \geq E_{\text {СПОЖ }}^{j},
$$

де $E_{\text {Спож }}^{j}$ - енергія споживання електронними компонентами транспондера: мікропроцесорів, підсилювачів тощо. 
Таким чином, математична модель системи попереднього визначення аварійності складних технологічних виробництв набуде вигляду

$$
\left\{\begin{array}{l}
E_{B X}^{j}+E_{j}^{i} \geq E_{\text {СПож }}^{j}, \\
t_{j} \geq t_{\text {нор. }} \\
\sum_{j=1}^{p} E_{B X}^{j}+\sum_{i=1}^{t} \sum_{j=1}^{p} E_{j}^{i} \mathrm{~s}_{i j} \rightarrow \min
\end{array}\right.
$$

Отримана математична модель системи попереднього визначення аварійності складних технологічних виробництв враховує основні складові системи: час передачі аварійної інформації, різні типи енергоспоживання тощо, що дає розробнику можливість будувати ефективні протиаварійні системи на базі визначення змін вібрації в роботі технологічних пристроїв.

Для перевірки адекватності отриманої математичної моделі було проведено кілька експериментів, де як джерело вібрації використано обертальний рух трьох робочих валів на базі двигунів ДПМ-20-Н3-01, на валах яких були закріплені ексцентрики для збільшення вібрації двигунів [2]. Як п'єзотранспондери використано консольні п'єзоперетворювачі на основі біморфних п'єзоелементів 7ВВ-12-9 фірми muRata [5], що складалися 3 п'єзоелементів $\varnothing 9$ мм товщиною 0,12 мм та пластин з латуні $\varnothing 12$ мм товщиною 0,1 мм. На трьох п'єзотранспондерах було виконано електроди різних розмірів.

При проведенні експериментів для змін вібраційних впливів змінювалися частоти обертів робочих валів (зміною напруги, що подається на двигун) та маси закріплених ексцентриків. Для проведення розрахунків згідно $з$ отриманою математичною моделлю було використано значення 3 [3, 6-8]. Електронну схему обробки даних 3 п'єзотранспондерів описано в [9, 10]. Проведені експерименти та порівняння теоретичних результатів з практичними виявило, що:

- при зміні вібраційної картини роботи кожного $з$ трьох двигунів відбувалася однозначна фіксація цієї події відповідним п'єзотранспондером;

- накопиченої в п'єзотранспондері енергії вистачало на передачу аварійної інформації

(C) М. Г.Томенко, В. I. Томенко, 2019 DOI: 10.24025/2306-4412.4.2019.187862 протягом 1,5-5 с, що цілком достатньо для фіксації цієї події у віддаленому центрі обробки аварійної інформації;

- різниця між значеннями теоретичних розрахунків та експериментально отриманими даними була не більша, ніж на $23 \%$, що можна вважати цілком прийнятним, враховуючи складність розрахунків п'єзоперетворювачів [3].

Висновки. В роботі запропоновано математичну модель системи попереднього визначення аварійності складних технологічних виробництв, яка враховує основні складові системи: час передачі аварійної інформації, різні типи енергоспоживання тощо. Проведені експериментальні дослідження на базі виявлення змін вібрації при обертальних рухах трьох робочих валів показали адекватність отриманої математичної моделі, причому різниця між значеннями теоретичних розрахунків та експериментально отриманими даними була не більша, ніж на $23 \%$. Отримана математична модель може бути використана розробниками при побудові ефективних протиаварійних систем складних технологічних виробництв на базі визначення змін вібрації в роботі обладнання.

\section{Список літератури}

[1] М. Г. Томенко, та О.О.Корецька, "Використання консольних п'єзокерамічних ідентифікаторів у вібродіагностиці при визначенні аварійних ситуацій потенційно небезпечних виробництв", Вісник Черкаського державного технологічного університету. Серія: Технічні науки, № 4, c. 68-72, 2018.

[2] М. Г. Томенко, та О. О. Корецька, "Підвищення надійності систем раннього визначення аварійності складних технологічних виробництв за допомогою безпровідних автономних п'єзотранспондерів", Наукові праці Чорномор. нач. ун-ту ім. Петра Могили комплексу «Києво-Могилянська академія». Серія: Комп'ютерні технології: наук.-метод. журн. Миколаїв: Вид-во ЧНУ ім. П. Могили, вип. 305 , т. 317 , с. $122-126$, 2018.

[3] В. М. Шарапов, М. П. Мусиенко, и Е. В. Шарапова, Пьезоэлектрические 
датчики: монография / под ред. В. М. Шарапова. Москва: Техносфера, 2006.

[4] Система радиочастотной идентификации на поверхностных акустических волнах. Компоненты и технологии. [Электронный ресурс]. Режим доступа: http://kite.ru/articles/rfid/2005_6_188.php

[5] Murata. Innovator in electronics. 7bb-12-9. [Online]. Available: https://www.murata.com/ products/productdetail?partno=7BB-12-9

[6] М. П. Мусиенко, "Теоретические основы, методы и средства структурноэнергосилового преобразования на основе полиэлектродных пьезокерамических элементов для систем управления", дис. д-ра техн. наук: 05.13.05, Одесса, 2006.

[7] М. П. Мусієнко, та О. О. Корецька, "Підвищення чутливості датчиків п’єзомагнітних тахометрів", на VII Міжнар. наук.-практ. конф. Датчики, прилади та системи - 2018, 17-21 верес. 2018 р. Черкаси: ЧДТУ, 2018, с. 9-12.

[8] М. П. Мусієнко, та О. О. Корецька, "Консольні п’єзоелектричні накопичувачі вібрації для ІоТ пристроїв", Наукові прачі Чорномор. нач. ун-ту ім. Петра Могили комплексу "Києво-Могилянська академія». Серія: Комп'ютерні технології: наук.-метод. журн. Миколаїв: Вид-во ЧНУ ім. П. Могили, вип. 296, т. 308 , с. $139-$ 145, 2017.

[9] О. О. Корецька, "Моделі та засоби побудови енергоефективних ІоТ пристроїв на базі п’єзокерамічних перетворювачів", дис. канд. техн. наук: 05.13.05. Черкаси, 2019.

[10] В. И. Бугаев, В. А. Дидук, и М. П. Мусиенко, "Сборщики энергии вибраций от Mide Technology приходят на смену батарейкам", Новости электроники (Москва), № 7 (141), c. 23-27, 2015.

\section{References}

[1] M. G. Tomenko, and O. O. Koretska, "The use of console piezoceramic identifiers in vibration diagnostics at the identification of potentially hazardous industries", Visnyk Cherkaskogo derzhavnogo tekhnolo- hichnogo universytetu. Seria: Tekhnichni nauky, no. 4, pp. 68-72, 2018 [in Ukrainian].

[2] M. G. Tomenko, and O. O. Koretska, "Improving the reliability of early warning systems for complex technological industries with the help of non-wire stand-alone piezotransponders", Naukovi pratsi Chornomor. nats. un-tu im. Petra Mohyly kompleksu «Kyievo-Mohylianska akade-miia». Seriia: Kompiuterni tekhnolohii: sci.method. journ. Mykolaiv: Vyd-vo ChNU im. P. Mohyly, iss. 305, vol. 317, pp. 122-126, 2018 [in Ukrainian].

[3] V. M. Sharapov, M. P. Musienko, and V. V. Sharapova, Piezoelectric sensors: monograph, V. M. Sharapov, Ed. Moscow: Tehnosfera, 2006 [in Russian].

[4] The radio frequency identification system on surface acoustic waves. Components and technologies. [Online]. Available: http://kite.ru/articles/rfid/ 2005_6_188.php

[5] Murata. Innovator in electronics. 7bb-12-9. [Online]. Available: https://www.murata.com/ products/productdetail?partno=7BB-12-9.

[6] M. P. Musiyenko, "Theoretical foundations, methods and means of structural-energypower conversion based on polyelectrod piezoceramic elements for control systems": D. Sc. dis.: 05.13.05, Odesa, 2006 [in Russian].

[7] M. P. Musienko, and O. O. Koretska, "The increase of sensitivity of piezomagnetic tachometers sensors". in VII Int. Sci.-Pract. Conf. Datchyky, prylady ta systemy - 2018, Cherkasy: ChDTU, 2018, Sept., 17-21, pp. 9-12 [in Ukrainian].

[8] M. P. Musienko, and O. O. Koretska, "Console piezoelectric vibration drives for IoT devices", Naukovi pratsi Chornomor. nats. un-tu im. Petra Mohyly kompleksu «KyievoMohylianska akademiia». Seriia: Kompiuterni tekhnolohii: sci.-method. journ. Mykolaiv: Vyd-vo ChNU im. P. Mohyly, iss. 296, vol. 308, pp. 139-145, 2017 [in Ukrainian].

[9] O. O. Koretska, "Models and tools for constructing energy efficient IoT devices based on piezoceramic transdusers", $\mathrm{Ph}$. D. dis. in Engineering: 05.13.05, Cherkasy, 2019 [in Ukrainian]. 
[10] V. I. Bugaev, V. A. Diduk, and M. P. Musienko, "Vibration energy collectors from Mide Technology replace batteries", Novosti elektroniki (Moscow), no. 7 (141), pp. 2327, 2015 [in Russian].

M. G. Tomenko, $P h . D$., e-mail: marina_tomenko@ukr.net

V. I. Tomenko, Ph D., associate professor e-mail: firech1996@gmail.com

Cherkasy Institute of Fire Safety named after Chornobyl Heroes of National University of Civil Defense of Ukraine

Onoprienko str., 8, Cherkasy, 18034, Ukraine

\section{MATHEMATICAL MODEL OF THE SYSTEM FOR EARLY DETERMINATION OF THE ACCIDENTS IN COMPLEX TECHNOLOGICAL MANUFACTURES BASED ON AUTONOMOUS PIEZOTRANSPONDERS}

For the early detection of emergencies and accidents on potentially hazardous or high-risk objects in complex technological processes, the changes in technical parameters of the equipment, such as vibration changes, can be used. To do this, we propose to use piezoceramic transducers. However, to build a complete system of complex technological process, it is necessary to use a large number of such sensors, which should work in a single identification system. To do this, the paper proposes a mathematical model of the system of preliminary determination of the accidents in complex technological industries, which is built on the principle of fixing the vibration changes of the equipment that precedes any accident. The model obtained takes into account: the number of control points at which vibration parameters are determined, the number of piezotransponders, the triggering threshold for each transponder, the energy previously accumulated in the system, the matrix of values of the possible placement of piezotransponders at control points, the time of transmission of the alarm, vectortape of fixation of transmission of an alarm signal identification, the time of transmission of an alarm signal, parameters of vibration at control points.

In order to check the adequacy of the mathematical model obtained, several experiments have been performed where the rotational motion of the working shafts is used as the source of vibration. Console piezoelectric transdurers based on bymorph piezoelectric elements are used as piezotransponders. When performing experiments to change the vibrational effects, the speed of rotation of the working shafts and the mass of the fixed eccentrics varies. The results of the experiments have shown that the energy accumulated due to vibration in the piezotransponder is sufficient for the transmission of emergency information, with the difference between the values of theoretical calculations and the experimentally obtained data not exceeding $23 \%$.

The resulting mathematical model can be used by developers to build effective anti-crash systems on complex technological productions of potentially hazardous or high-risk objects.

Keywords: mathematical model, emergency situations, piezotransponder, vibration, energy.

Стаття надійшла 29.10.2019

Прийнято 19.11.2019 